\title{
Universidade e Empresa*. (O Formando em Relação ao Exercício Profissional)
}

\section{Luiz Geraldo de Carvalho}

Ao darmos início a esta contribuição, referente ao estudo do tema Partida Para o Entrosamento Universidade - Empresa, desde logo desejamos considerar os atributos dos elementos que o constituem, valendo-nos, para isto, das definições do referido binônio:

UNIVERSIDADE - vocábulo derivado do latim - universitate - significa o conjunto de estabelecimentos de ensino de grau superior dedicados à especialização profissional e científica, pelo ensino das ciências, o fomento das pesquisas e o preparo das elites de cientistas.

EMPRESA - é o conjunto unitário de bens e de pessoas, dirigido à produção.

Desde o início, já podemos divisar um universo amplo, encerrando os mais diversos interesses e aspirações da comunidade, que deverá ser atendido.

O dimensionamento deste contexto poderá ser avaliado a partir das 72 profissões universitárias que se desdobram em cerca de 528 especialidades. Esta diversificação de atividades, verdadeira imposição da sociedade moderna, se na sua origem teve como base a necessária divisão do trabalho, não tardou a assumir características específicas para melhor atender às exigências que o progresso passou a apresentar. Assim, à medida que as ciências e a tecnologia se desenvolveram, novas especialidades surgiram, impondo-se como indispensáveis profissionalmente.

\footnotetext{
* O presente trabalho, apresentado na ADESG, como tema básico subordinado ao título Integração Universidade-Empresa, interessa a todas as áreas da USP e, em especial, ao futuro advogado, já que o antigo artesanato é substituído pela empresa.
} 
A constelação crescente de oportunidades que o mundo moderno oferece no mercado de trabalho nos leva a considerar a importância da interação Universidade-Empresa, que na qualidade de órgãos meio têm grande participação na conquista do objetivo síntese - o bem comum.

Em São Paulo, contamos com diversas Universidades, ainda jovens e muitas Escolas de Ensino Superior.

Vale lembrar:

- Universidade de São Paulo - instituída por Armando de Salles Oliveira, em 1934 e instalada em 1941.

- Pontifícia Universidade Católica de São Paulo - criada em 1946.

- Universidade Mackenzie de São Paulo - fundada em 1952.

- Fundação Universitária do ABC - criada em 1969.

- Universidade Estadual de Campinas - Fundada em 1970.

- Universidade Estadual Paulista - criada em 1976 e com "campus" em Ilha Solteira.

Além das Faculdades, Institutos e Escolas que fazem parte das Universidades, há grande número de Escolas de Ensino Superior que, somadas às primeiras, atinge a cifra de 853 no seu cômputo total.

Por outro lado, o Parque Empresarial de São Paulo é representado por cerca de 50.000 empresas localizadas na Capital e nas 57 cidades mais importantes do interior.

Países como o nosso, que mediante a arrancada para 0 desenvolvimento estão assumindo proporções de potência emergente, encontram cada vez mais um sem-número de óbices internos e externos, cuja relevância põe, por vezes, à prova, a eficácia da Política Nacional formulada.

Nos dias em que vivemos, o Desenvolvimento e a Segurança são, cada vez mais, produtos da inteligência nacional e, como decorrência, estaremos tanto mais próximos dos Objetivos Nacionais quanto mais forem acionados os sistemas técnico-científicos da Nação.

O ritmo veloz das ações, reclamado pelos interesses vitais a serem atingidos, só poderá ser alcançado mediante um desen- 
volvimento qualitativo e quantitativo dos recursos humanos, adequadamente planejados. Para tanto há que se agilizar, prioritariamente, o desempenho de alguns fatores das Expressões do Poder Nacional, a fim de que os efeitos deles resultantes venham em socorro das necessidades mais sentidas. Tratando-se de Expressões integradas e harmônicas, e tendo em conta as suas características dinâmicas, haverá sempre oportunidade para proceder ao balanceamento conveniente dos seus elementos.

Logo após a II Guerra Mundial, o mundo teve oportunidade de contemplar as discrepâncias sócio-econômico-culturais que caracterizavam as diversas nações e criou-se naquele então o conceito de nação subdesenvolvida. Muitos anos mais tarde, grupos de nações foram distribuídos em três mundos, $1 .^{\circ}, 2 .^{\circ}$ e $3 .^{\circ}$, segundo um critério decrescente do poder e potencial sócio-econômico-cultural. Mais recentemente, em conseqüência da política da OPEP relativa ao petróleo, estas posições tiveram que ser revistas na sua maioria, uma vez que países ricos se tornaram menos ricos e países pobres passaram a mais pobres.

MARCEL GANZIN, especialista em problemas da nutrição e Chefe da Divisão de Política Alimentar e de Nutrição do FAo, estabelece uma confrontação entre os recursos econômicos decisivos no mundo de hoje - cereais e petróleo - de acordo com a sua distribuição, obtendo como resultado uma nova classificação das nações, em 4 categorias:

1. produtoras de petróleo e de cereais

2. produtoras de petróleo e importadoras de cereais

3. importadoras de petróleo e produtoras de cereais

4. importadoras de cereais e de petróleo

Supondo que somente estes dois parâmetros traduzissem de maneira absoluta a escala de valores capaz de classificar as nações, já teríamos aqui dois indicadores a mostrar os caminhos da ciência e tecnologia, necessários para superar um estado inferior de desenvolvimento. Entretanto, múltiplos fatores entram em jogo quando se pretende avaliar o grau que o desenvolvimento de uma nação atingiu, pois nesta oportunidade estaremos, na verdade, aquilatando as Expressões do Poder Nacional.

Restringindo-nos ao nosso tema, admitiremos que ao partir para uma política de entrosamento Universidade Empresa, há 
que se aferir, preliminarmente, a capacidade do Poder Nacional, considerando principalmente as suas expressões Política, Psico-social e Econômica em confronto com os objetivos propostos e os óbices a serem vencidos. Satisfeitas estas condições, poderemos passar à efetivação da partida para atender aspectos conjunturais propostos.

Não há dúvida de que o produto final da preparação universitária é a formação de recursos humanos altamente qualificados. Estes recursos deverão satisfazer às necessidades das ações correntes, mediante previsão e provisão coerentes com os aspectos realísticos a que nos propomos a atingir e que fazem parte de um contexto maior e a mais longo prazo.

Quando nos referimos ao binômio Universidade - Empresa, logo nos vem à mente outro binômio - ciência e tecnologia. Assim como a tecnologia tem suas bases nos trabalhos e pesquisas científicas, as empresas têm suas raízes implantadas, direta ou indiretamente, nas universidades. Algumas vêm mantendo este intercâmbio há longo tempo. É o caso da Bayer, Indústria alemã de produtos químicos, cujas atividades se iniciaram no século passado, na Alemanha e que, em nosso país, há oito anos vem distribuindo prêmios de valor aos melhores trabalhos sobre Medicina Tropical, realizados no meio universitário. Este relacionamento é também observado com diversos países da Europa.

No campo da medicina, ${ }^{1}$ ainda podemos citar o exemplo observado nos Estados Unidos e Canadá. A maioria dos hospitais destes países se constitui em empresas particulares e mantém convênio com uma ou mais Universidades, com a finalidade de ensino, pesquisa e treinamento. Não basta entretanto, que o hospital ofereça excelente equipamento, boas equipes e assistência médica de alto nível. Torna-se necessário, também, que apresente uma relação de profissionais de reconhecida capacidade didática e programas que correspondam aos currículos das universidades. Todas estas condições deverão ser examinadas e aprovadas pela "American Medical Association" bem como pela "American Hospital Association", as quais passarão depois a fiscalizar e avaliar a execução dos programas apresentados. O treinamento se estende à área médica e pára-médica, atendendo a estudantes, recém-formados e profissionais

1. No campo do direito, inúmeras sociedades de advogados manitêm contato com Universidades, dando oportunidades ao futuro profissional do direito. 
já formados há algum tempo e que desejem fazer uma reciclagem da respectiva especialidade. Com exceção dos estudantes, todos se encaminham a setores especializados (médicos, enfermeiras, assistentes sociais, nutricionistas, educadoras sanitárias, técnicos, etc.).

\section{A título de ilustração, referimos:}

1. Harper Hospital - Detroit - campo de treinamento e ensino da Wayne University.

2. Mount Sinai Hospital of Greater Miami - hospital escola, recebe internos e residentes da Universidade de Miami.

3. Rehabilitation Institute of Montreal - é um hospital de ensino, onde médicos que se especializam em fisiatria podem completar a residência e onde são aceitos internos em todas as disciplinas pára-médicas, relacionando-se com a reabilitação.

Nos Estados Unidos, o estágio dos estudantes-internos ${ }^{2}$ é aprovado pela "The American Medical Association" e os programas de residência-médica, em todas as especialidades médicas e cirúrgicas, são aprovadas pela "American Speciality Boards".

Em nosso meio já existe algo semelhante no campo da medicina, mas os resultados estão muito aquém da expectativa. Isto se dá principalmente devido à falta de instruções normativas e à inexistência de órgãos capazes de controlar o desempenho e a qualidade dos programas desenvolvidos.

Não obstante, muitos exemplos encorajadores, na área das pesquisas e desenvolvimento de projetos já podem ser citados, os quais partindo de Universidades (USP, UNICAMP, PUC, MACKENZIE) e de escolas isoladas (FEI, MAUÁ) vêm beneficiando empresas públicas e algumas empresas privadas, em diversos campos da atividade. Em destaque devemos lembrar as múltiplas atividades do CTA, as quais já conseguiram transpor as fronteiras do Brasil.

No decurso da última década, nota-se a prioridade que a ação governamental vem dando às áreas de educação e desen-

2. No Brasil, estágio e estagiário são vocábulos que integram a terminologia jurídica, visto que se tornaram realidade em nosso país, traduzindo - período de tempo de prática advocatícia e a pessoa que já trabalha em escritório, cursando ainda a Universidade. 
volvimento científico e tecnológico. Este aspecto da Política Nacional se traduz não só pela ampliação das oportunidades de acesso ao estudo de terceiro grau, mas também pela reformulação dos programas, com a finalidade de formar pesquisadores e pós-graduados em número cada vez maior. Paralelamente, surgiram centros, sistemas e áreas de pesquisa diversificados em amplo espectro de interesses nacionais, compreendendo desde problemas agropecuários até assuntos ligados à cibernética, fontes energéticas e programas aeroespaciais.

São diversas as entidades criadas pelo Governo, para dar apoio financeiro e fomentar a pesquisa e outras atividades universitárias, verdadeiros insumos ao sistema educacional de terceiro grau, bem como à pesquisa e ao desenvolvimento de projetos.

A título de referência lembramos:

1. CAPES - Centro de Aperfeiçoamento do Pessoal do Ensino Superior - Ministério da Educação.

2. CNPQ - Conselho Nacional de Pesquisas - Ministério do Planejamento.

3. FAPESP - Fundação de Amparo à Pesquisa - mantida pelo Governo do Estado de São Paulo.

4. FINEP - Financiamento de Estudos e Projetos ligados diretamente à Presidência da República A sua área operacional está relacionada com aquisição de equipamentos, material de consumo e prestação de serviços a terceiros.

5. FUNAT - Fundo de Amparo à Tecnologia - criado por Castello Branco a 28.02.67, destina $15 \%$ da receita do Ministério de Indústria e Comércio, relacionada com desenvolvimento tecnológico e mais elevada quantia anual ao Instituto Nacional de Tecnologia (INT) incumbido de "funções de supervisão, orientação, execução e fiscalização do programa tecnológico nacional".

6. FUNTEC - Fundo Nacional de Desenvolvimento Científico e Tecnológico - encarregado de implantar o Plano Básico de Desenvolvimento Científico e Tecnológico, 1969.

7. SBPC - Sociedade Brasileira para o Progresso da Ciência. 
8. SUBIN - Secretaria de Cooperação Econômica e Técnica Internacional - Secretaria do Planejamento da Presidência da República - tem por finalidade propiciar o intercâmbio cultural e científico de entidades e professores nacionais e estrangeiros.

Como é fácil depreender do que até aqui foi ventilado, o entrosamento Universidade-Empresa já pode ser aceito como um fato, caracterizando-se apenas por ser quase fortuito, pois na maioria dos casos é contingente e, quando não, movido por relacionamentos de caráter pessoal. É o caso da cooperação da Termomecânica S.A. com o CTA, cujos excelentes resultados vêm mantendo vivo o interesse de ambos os lados.

Desta maneira, vão-se criando sistemas interdependentes que, ao obterem êxitos, passam a acentuar o entrosamento e a propagar os sucessos conseguidos, em um horizonte cada vez maior.

Os estímulos financeiros oferecidos pelo Poder Nacional atestam que a Política Nacional reconhece a validade deste consórcio, a ponto de oferecer subsídios financeiros indispensáveis ao desenvolvimento e multiplicação das ações já iniciadas.

Paralelamente a estas providências, entendeu o Governo ser oportuno legislar sobre a matéria e assim sancionou a Lei n. ${ }^{\circ}$ 6.494, de 7 de Dezembro de 1977, que dispõe sobre estágios de estudantes de estabelecimentos de ensino superior e de ensino profissionalizante de $20^{\circ} \mathrm{Grau}$ e Supletivo e dá outras providências.

Considerando o amplo espectro de possibilidades universitárias de um lado, e, de outro lado, as inúmeras atividades empresariais, torna-se evidente a repercussão deste entrosamento na Segurança e no Desenvolvimento nacionais, pois ao constituirem um todo técnico-científico, estarão não só promovendo o aprimoramento dos elementos básicos da Nação, mas ainda capacitando cada vez mais as Expressões do Poder Nacional.

Assim, já podemos admitir um fluxo de informações e de recursos entre a Universidade e a Empresa, com conotações marcantes no campo das ciências exatas, biológicas, nas letras e nas artes.

No campo das letras, é mister que nos refiramos à tradicional Faculdade de Direito de São Paulo, fundada em 1827 e que talvez tenha sido a pioneira a realizar o encontro Universidade-Empresa, quando seus acadêmicos já credenciados como "solicitadores" procuravam afamadas Bancas de 
Advocacia, como ponto de partida das atividades práticas relativas à profissão que escolheram.

0 enfoque que demos até agora à matéria em estudo, nos permite admitir que a situação do formando, diante da espectativa de trabalho, é de incerteza, uma vez que mal conhecendo o mercado de trabalho e suas possibilidades, em geral aguarda o registro do diploma para, só depois, iniciar a procura do emprego.

Os estágios compulsórios (estudantes de último ano freqüentando hospitais, indústrias e outras empresas) ou voluntários (iniciativa particular que parte de estudantes ou empresário) em geral não são suficientes para retratar a realidade que espera os futuros profissionais, visto como a responsabilidade das ações praticadas está na alçada de terceiros.

A distância entre a Universidade e a Empresa ainda é um dos principais óbices; isto porque enquanto a primeira se dedica mais ao campo da ciência pura, a segunda, a despeito de suas raízes científicas, está interessada no campo das ciências aplicadas, além de ser movida por interesses comerciais e pelo fator tempo, indispensáveis à sua sobrevivência.

Os projetos e estudos realizados em nível de Universidade a fim de serem utilizados pelas empresas (estatais ou privadas), em geral se estendem por muito tempo. Como exemplo lembramos algumas referências feitas pelo Professor Hélio Guerra, da Escola Politécnica da USP, por ocasião do painel Universidade-Empresa :

1. Fundição Tupi - Implantação de Centro de Pesquisas - 53 meses.

2. Digibras S.A. - Marinha - Desenvolvimento do primeiro computador digital brasileiro - 52 meses.

3. Metrô de São Paulo - ensaios eletromecânicos ambientais - Manutenção — 46 meses.

4. Telebrás - Central Telefônica Eletrônica - Protótipo de Central com Comutação Temporal — 43 meses.

Esta morosidade, no desenvolvimento dos trabalhos científicos nas Universidades, constitui um dos principais óbices que a Empresa encontra ao tentar um entrosamento mais efetivo. Em decorrência há importação de "Know-how" que sobre a vantagem do tempo garante a manutenção do mercado consumidor. Além disto, existem barreiras potenciais que 
poderiam ser traduzidas pela pouca confiabilidade que as Universidades inspiram, dada a imprecisão dos prazos e custos, relativos a trabalhos e pesquisas que devam ser realizados.

No campo da Química, o mesmo se observa: acresce ainda que o estágio dos universitários em Empresas, apesar de se tornar cada dia mais freqüente, não é uma regra geral porque :

1. não é obrigação curricular na maioria das escolas superiores.

2. não está regulamentado.

3. em geral é provocado pela empresa.

$\mathrm{Na}$ área médica, a procura pela empresa (privada e oficial) - Hospital - já é prática de longos anos e cada vez mais disputada, principalmente pelos recém-formados que procuram realizar a "residência". Não obstante o Ministério da Educação registrar o diploma do médico, dando-lhe autorização para o livre exercício da medicina em todo o território nacional, ele terá também que se inscrever no Conselho Regional de Medicina para que possa exercer suas funções. Ao lado disto, como lei de usos e costumes, existe o conceito firmado de que melhor médico é aquele que fez "residência". Esta situação repercute no mercado de trabalho que então passa a ser mais permeável aos que assim estão credenciados, exigindo-se comprovante de especialidade. Tornou-se assim a residênciamédica o início de uma especialização exigida pelo mercado de trabalho.

Em que pese o esforço que os estudantes e recém-formados fazem para, em um mercado de recursos humanos altamente competitivo, obterem êxito profissional, uma boa parcela fica fora da competição, obrigando-se uns a abraçar outra especialidade enquanto que outros se submetem à quebra dos padrões autênticos, tangidos pela necessidade de garantir economicamente a sobrevivência.

Diante deste panorama, há que se estabelecer uma Estratégia Nacional relativa ao entrosamento Universidade-Empresa que permita uma PARTIDA DE DiREITo, uma vez que a PARTIDA DE FATo já foi dada, mas ainda não atingiu os objetivos desejados por falta de organização e métodos adequados.

Voltando a considerar o raciocínio já feito, baseado na interação dos sistemas, sugerimos que a referida Estratégia deva preparar e aplicar o Poder Nacional, considerados os 
óbices existentes ou potenciais já referidos, para alcançar e manter os objetivos fixados e inseridos na Política Nacional. Para tanto, será preciso que nos valhamos da tônica imprimida pelo atual Governo à Política Nacional: o máximo de Desenvolvimento com o mínimo de Segurança compatível.

Diante desta filosofia de governo, nos animamos a reviver a idéia da criação do Ministério da Ciência e Tecnologia, tão vivamente aceita e aplaudida inicialmente a ponto de levar o Presidente Castello Branco a instituir o "cargo" de Ministro Extraordinário para a Ciência e a Tecnologia.

Os obstáculos que se antepõem à criação do referido Ministério estão ligados a um círculo vicioso em que se geram mutuamente a falta de recursos e a falta de tecnologia.

O planejamento criterioso da aplicação de recursos para o desenvolvimento do binômio Universidade-Empresa, passa a ser cada vez mais uma necessidade premente, visto como desta interação é que deverão advir os princípios nutrientes da Segurança e Desenvolvimento.

O Ministério da Ciência e Tecnologia, através de normas, regulamentos e programas, disciplinará as ações de maior importância para as diversas regiões do país, passando então a atender de maneira coerente os interesses e aspirações da Nação e concretizando de maneira ampla e de direito, a PARTIDA PARA o EnTROSAMENTo UNIVERSIDADE-EMPRESA. 